\title{
Social Media Marketing as a Tool to Manage Luxury Brands
}

\author{
Giuseppe Granata ${ }^{1}$, Giancarlo Scozzese ${ }^{2}$ \\ ${ }^{1}$ Department of Economics and Law, University of Cassino and Southern Lazio, Cassino, Italy, \\ ${ }^{1}$ E-mail g.granata@unicas.it (Corresponding author) \\ ${ }^{2}$ Department of Human and Social Sciences, University for Foreigners, Perugia, Italy
}

\begin{abstract}
To try to understand what the role of social media is in the process of starting and developing brand value. Furthermore, it will be examined how the transformation from brand loyalty to "brand trust" takes place. A survey will be carried out to bring participants to navigate on the Facebook page of a luxury brand. The aim is to measure the role of Social Media Marketing, by completing a questionnaire, in the process of developing brand value and strengthening affection for the brand. Thanks to an analysis of the reference literatures and through an analysis of the case, we have come to understand how, in luxury, social media contribute to developing brand value and strengthening affection

Key words Brand Management, Consumer Behaviour, Luxury Brands, Social Media Marketing, User-Generated Content

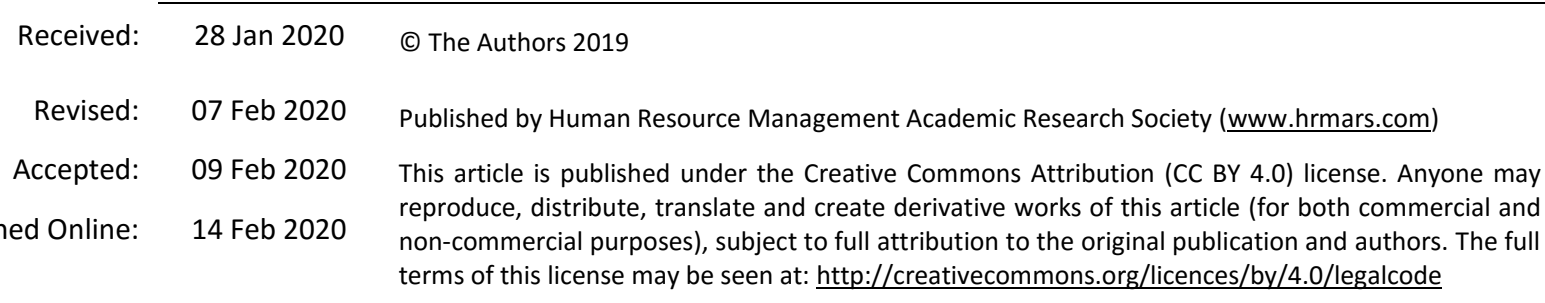

\section{Introduction}

The digital revolution and the birth of Web 2.0, as well as new consumption habits, have radically changed the current society and this has affected the marketing and communication strategies at the managerial level. In recent years the luxury industry has been strongly influenced by the rapid evolution of digital technology, technology and the Internet. The use of internet and new technologies has contributed to the growth of the market and its various sectors, with an advantage for the luxury industry. It was a challenge to adapt to the new process, times have been slow given that this market has always adopted a strategy based on supply and not on demand, because luxury products attribute prestige status and stand out for their excellent quality, the high price, the highly exclusive and symbolic character. Instead, the principles of the Internet are democracy and accessibility that at first glance appear to be in contrast with the characteristics of luxury just exposed. Luxury consumers are highly digital, mobile, social and extremely demanding and are always looking for continuous information, news and dialogue with the brand; they love word of mouth and use different channels and tools to communicate and express their opinions. Through social media they have the opportunity to review and discuss products, events and ideas on online forums, playing an increasingly influential role in shaping the public perception of luxury brands.

The developments in Web 2.0, defined by users-generated contents (UGC) and social networking sites, led to significant implications for the consumer and the study of cultures of consumption (Beer and Burrows, 2010). Internet has enabled a new era of UGC, threatening the hegemony of traditional content generator like advertising and experts or as the primary sources of information (Dhar and Chang, 2009). The multi-channel marketing and integrated has pervaded the web and Social Network are tools that give 
significant input to the processes of communication, but at the same time, it also detects instruments output both internal and external organizations; Enterprises adoption "competitive strategies" by defining symbolic meanings, in order to be always present among consumers (Heil et al., 2010 ; Tynan et al., 2010) , multiplicand the levels of loyalty and developing incremental levels of affection. Luxury brands have to evoke the uniqueness and exclusivity due to high quality, premium prices and controlled distribution.

The main channel of retail sales for luxury brands is represented by offline stores, remains in any case the problem of having to oversee the different channels of communication among them, the online channel in this case represented by the social network sites that contribute to the creation of virtual communities of brand, experience and unconventional brand value improvement (Muniz and O'Guinn, 2001). In parallel, the web is a "free place" where everyone can express themselves in a more or less controlled (Stokburger-Sauer, 2010). The garrison of that channel is key to reducing the impact on the brand may be negative from stakeholders to reduce its value and, therefore, in need of supervision that channel, strengthening the Communication in an incremental process and continuous.

The work, with the support of the literature as reference, through the analysis of a case, intends to uncover any evidence that, in luxury, helping to develop the brand value and strengthen its affection.

In this regard, the present research will examine the marketing potential of social media as a tool for luxury brand management and will address the challenges luxury brands encounter in managing their interactive and dynamic relationships with consumers who utilize social media (Granata and Moretta 2014).

\section{Social media and luxury brands}

Luxury brands represent a significant part of sales, especially, in the fashion industry. The turnover of Chanel, one of the biggest luxury brands in the world, was almost ten billion dollars in 2017, with operating profit of about 2.7 billion dollars and 11 billion dollars in 2018. Although the economy has had a sharp downturn in recent years, Chanel's operating profit and net turnover manage to grow. The luxury goods industry implies the need for a better comprehension of the driving factors that encourage the consumption of luxury brands through new forms and new communication systems. This research is based on the management of the luxury brand in current social and media environments and aimed to identify new forms of communication through the web. As a result, this research focuses on the psychosocial mechanisms underlying the unique integration of luxury brands and social media, on the basis of which luxury brands of company-generated content and consumer-generated content can coexist. Thanks to the rapid growth of UGC (user-generated contents) included in multiple social media contexts, consumers always have access to the opinions of other consumers, even those who are outside of their social circles (Dhar and Chang, 2009). Such social media as Facebook and Twitter are a form of virtual community development, "digital social spaces that allow groups to exchange and share opinions, messages, news, etc." (Granata and Scozzese, 2018)

Community members, unlike traditional media in which users consume content passively, members of digital communities create content through active participation.in these innovative systems. Past research has shown that consumers prefer to listen to the suggestions and recommendations of other consumers and, especially, professional reviews by critics with particular reference to hedonic products (Dellarocas et al., 2007). This discovery implies the potential impact of UGC on hedonic brands incorporated into social media through brand management (Granata and Scozzese, 2017).

This study has the main objective of testing the potential of social media marketing to manage luxury brands. In order to investigate the real consumer perception of luxury brands on the world market, through Chanel's Facebook fan page which is one of the most famous luxury brands in the world? This research also required participants to examine Chanel's active Facebook pages to evaluate the brand they use (for example, the home page, updates, photos, videos, information, user-generated content, comments), indicating the capacity of how the luxury brand embedded in social media is perceived and the behavioral intention to access social networks to perform online searches for luxury brands. By visiting the Facebook pages related to Chanel, it is possible to stimulate the interest of consumers to use the web for online shopping. This advantage, in turn, can influence consumer behaviour by visiting Chanel and other social media Facebook pages where a wide range of UGC related to the brand are available. Therefore, the first 
research question (RQ1) examines the relation between consumers' willingness to use Facebook for shopping and their intentions to visit the Chanel page on social media:

RQ1. Is there a correlation between consumers' interest in using Facebook for online research in order to shop and their intention to visit a page of the luxury brand on social media?

It is increasingly common for users to search for online products and offline purchases. That is, they see, inform and choose online and then make purchases using traditional methods, such as offline stores (Heil et al., 2010). This mechanism is a very important data of the consumer research survey, both for interactive marketing and for online shopping. The classical internet model has given way to hybrid forms of e-commerce in which companies combine their traditional activities with web channels. These hybrid companies try to get competitive advantages of cost reduction, value-added services, and expansions in new markets by integrating their physical and virtual stores (Granata, 2018).

As a result, e-commerce and online communication could become a threat to brands with offline stores only. This phenomenon of users doing online searches and offline purchases is very much used especially for luxury goods. Because we consider the high purchase price and the high risks of buying counterfeit products. In this case, consumers of luxury brands perform purchasing behaviour by visiting the online stores of a luxury brand and then making purchases in traditional stores. So, social media (Facebook, Twitter, YouTube, etc.) can serve as sales support for luxury brands. It is very common among users to access online before making a purchase. Consumers use this method to evaluate the quality of the product or service, draw information and opinions from other users. Information that can be in text, photos or video, in order to convey their opinions. Thus, they reduce uncertainty and improve the efficiency of consumer online research (Dwyer, 2007) in the process of purchasing luxury brands.

Thus, the second research question (RQ2) examined the relation between consumer use of a luxury brand social media and consumer intentions of online researching and offline purchasing:

RQ2. Is there a correlation between the intention of consumers to visit social media of a luxury brand, i.e. to conduct an online research and purchase offline?

The previous research in the settotre identified two important functions of luxury brands: the attitude-based theory (Shavitt et al., 1992) of the expressive function of value and the social function (Wilcox et al., 2009). When consumers have a value-expressive attitude towards luxury brands, they are motivated to use them as a form of self-expression to show their core values. For example, a consumer purchases a Chanel bag because this brand reflects his personality, communicating these values to others.

When consumers have a social attitude towards luxury brands, they are motivated to consume them to convey a particular social image and gain approval in social situations. Another example may be that a consumer could buy a Chanel bag because the brand reflects a status symbol, so the goal is to create a particular image in social contexts. This research shows that consumer perception of luxury brands involves both a self-expression (value-expressive) function (H1), and an impression management (social value) function $(\mathrm{H} 2)$ and that these two functions are positive consumer attitudes towards a luxury brand:

H1. Perception of the expressive value of consumers towards a luxury brand is a self-expression.

$\mathrm{H} 2$. Perception of the social value of a luxury brand consumers is an expression of impression management.

The positive growth of the luxury good industry reflects the trend that consumers are always trying to address towards products that provide emotional benefits (Hagtvedt and Patrick, 2009). Hagtvedt and Patrick theorized that the connotations of pleasure that accompany a luxury brand are the utilitarian advantages conferred by the value of the brand. Existing literature indicates that two different commercial motivations (hedonic versus utilitarian) (Babin et al., 1994) influence online shopping attitudes (Childers et al., 2001) and the flow of the experiences of purchasing online (Novak et al., 2003).

Therefore understanding the role of consumer hedonic motivation is critical to the management of the luxury brand. In addition to structuring models of equations, the research examined the influence of motivations on consumers (hedonic motivation versus utilitarian motivation) measured through the main variables to answer the following research question:

RQ3. Is there a significant systematic difference between consumers who make a utilitarian choice and those who make a hedonistic choice before accessing the pages of luxury brands on Facebook? 


\section{Methodology of research}

The participants were 250 young students. Participation was voluntary and there was no financial compensation. The participants were invited to a laboratory equipped with a network computer, where pre-loaded online questionnaire was submitted as a tool of cross-sectional study. The participants opened the online questionnaire, designed to measure the perception of luxury brands and attitude to the Chanel brand, and then a page with the following inscription appeared: "Today, you will have the opportunity to visit the Chanel Facebook page. You will spend a few minutes on this page reading various articles". After explaining how it works, the participants published the Chanel Facebook page for about 10 minutes. At the end they completed the questionnaire designed to measure their satisfaction with the Facebook page of the luxury brand.

\section{Limitations and suggestions for future research}

Several limitations of this research can serve as a useful point for future investigations. The limits of the research are recognized in relation to the external validity and influence of various motivations.

Thus, the limits can help us to find the way to remove these limitations in the future. First, the participants of the experiment were asked to visit Facebook page of a specific brand instead of choosing a page by themselves. The first fundamental concept is that Facebook users often receive friend requests and they are exposed to various links to brands and companies on social media.

Therefore, the current search procedure has an acceptable external validity. Another motivation is that students are potential future consumers of luxury goods and at the same time are social media users. Obviously young people are very active users on social media compared to older consumers who buy luxury brands. Despite the exploratory nature of the present research and the advantage that the participants are alike in controlling other external variables (for example, the income, the chronology of the purchases, the experience with brands), the evaluation of the students who use Facebook to search for luxury brand is still problematic.

Future research can greatly benefit from a rigorous analysis of the content of current consumer comments and significantly contribute to the creation and promotion of UGC.

Despite some limitations, this research represents an exploratory step towards understanding UGC dynamic roles and using social media in training and maintaining the emerging triad culture: consumerbrand-consumer.

\section{Discussions and conclusions}

This research tests the marketing potential of social networks for managing luxury brands. SEM1 (Search Engine Marketing) analysis was done to clarify the dynamic relations between perceptions of expressive and social value features of luxury brand consumers, brand attitudes before visiting Facebook page of a specific luxury brand, brand attitudes after visiting Facebook page, satisfaction with a luxury brand with a Facebook page interface and the intentions of using social media for luxury brands to make a purchase.

The results of the SEM analysis, in general indicate that consumer satisfaction, through the use of Facebook for the search for luxury brands, is positive.

This research is among the first to examine the evaluation of luxury brands by consumers through the world of social media. Furthermore it has allowed testing an integrative model including the consequences of attitudes towards luxury brands in terms of UGC and Social Network dynamics. However, it has several managerial implications for branding. First of all, in order to stimulate positive attitudes among consumer goals, luxury brand marketing managers must understand and discover a deeper understanding that consumers buy luxury brands (Tasi, 2005). The present research to answer this question has examined in depth the role of the hedonistic consumer, the motivations of a behavior of choice (luxury vs. necessity), their perceptions of the expressive value and the social functions of luxury brands. Furthermore, this research differs from the traditional paradigm of the consumer brand dyad and refers to the new paradigm of the consumer-brand-consumer triad (Muniz and O'guinn, 2001). Thus, this research provides managerial implications for marketing in order to manage a social brand through social networks and implies the importance of creating social network interfaces that satisfy the needs of consumers in 
promoting a favourable brand attitude. Consumers actively use social media providing real evidence of brand perceptions and attributes.

Ultimately, luxury brand managers to advertise luxury brands are interested in using social media marketing. Through the creation of events and online initiatives, they must build an interactive relationship with consumers and talk to them. 1 Marketing is directed towards the acquisition, sale and analysis of usage and purchase data through search engines.

\section{References}

1. Babin, B. J., Darden, W. R. \& Griffin, M. (1994), "Work and/or fun: measuring hedonic and utilitarian shopping value", Journal of Consumer Research, Vol. 20, pp. 644-56.

2. Beer, D., \& Burrows, R. (2010), "Consumption, presumption, and participatory web cultures: an introduction", Journal of Consumer Culture, Vol. 10 No. 1.

3. Childers, T. L., Carr, C. L., Peck, J., \& Carson, S. (2001). Hedonic and utilitarian motivations for online retail shopping behavior. Journal of Retailing, 77(4), 511-535. https://doi.org/10.1016/S00224359(01)00056-2

4. Dellarocas, C., Zhang, X. M., \& Awad, N. F. (2007), "Exploring the value of online product reviews in forecasting sales: the case of motion pictures", Journal of Interactive Marketing, Vol. 21 No. 4.

5. Dhar, V., \& Chang, E. A. (2009), "Does chatter matter? The impact of user-generated content on music sales", Journal of Interactive Marketing, Vol. 23 N. 4.

6. Dwyer, C. (2007) "Digital Relationships in the 'MySpace' Generation: Results from a Qualitative Study." Proceedings of the 40th Hawaii International Conference on System Sciences (HICSS), Hawaii,

7. Granata G., \& Tartaglione, M. A. (2014) Social media for the management of luxury Brand - 3rd Business systems Laboratory International Symposium - Perugia.

8. Granata G., \& Scozzeze G., (2017), The Influence of Virtual Communities in Marketing Decision in International Business Research, Vol. 10 n 12, ISSN 1913-9004, doi:10.5539/ibrv10n12p191.

9. Granata, G. (2018), Strategies and Tools of Social Media Marketing in the Luxury Fashion Industry, in International Journal of Management Sciences and Business Research, Dec-2018 Vol-7, Issue 12.

10.Granata G., \& Scozzeze G. (2018), The Evolution of Virtual Marketing to improve Business Communication, in International Business Research, Vol. 11 n. 12, doi:10.5539/ibr. v11n12p105.

11.Hagtvedt, H., \& Patrick, V. M. (2009), "The broad embrace of luxury: hedonic potential as a driver of brand extendibility", Journal of Consumer Psychology, Vol. 19 No. 4.

12.Heil, O., Lehmann, D., \& Stremersch, S. (2010), "Marketing competition in the 21st century", International Journal of Research in Marketing, Vol. 27 No. 2.

13.Muniz, A. M., \& and O'Guinn, T. C. (2001), "Brand community", Journal of Consumer Research, Vol. 27 No. 4.

14.Novak, T. P., Hoffman, D. L., \& Duhachek, A. (2003) The Influence of Goal-Directed and Experiential Activities on Online Flow Experiences, Journal of Consumer Psychology 13(1/2), p. 3-16

15.Shavitt, S., Lowrey, T. M., \& Han, S. (1992),. Attitude functions in advertising: The interactive role of products and self-monitoring. Journal of Consumer Psychology.

16.Stokburger-Sauer, N. (2010), "Brand community: drivers and outcomes", Psychology \& Marketing, Vol. 27 N. 4.

17.Tasi, S. (2005), "Impact of personal orientation on luxury-brand purchase value", International Journal of Market Research, Vol. 47 No. 4.

18.Tynan, C., McKechnie, S., \& Chhuon, C. (2010), “Co-creating value for luxury brands”, Journal of Business Research, Vol. 63 No. 11.

19.Wilcox, K., Kim, H. M. \& Sen, S. (2009). Why Do Consumers Buy Counterfeit Luxury Brands? Journal of Marketing Research. 